\title{
THE
}

\section{The Effect of Loyalty Program Fees on Program Perceptions and Engagement}

\author{
Christy Ashley \\ University of Rhode Island, christyashley@uri.edu \\ Erin A. Gillespie \\ Stephanie M. Noble
}

Follow this and additional works at: https://digitalcommons.uri.edu/cba_facpubs

The University of Rhode Island Faculty have made this article openly available.

Please let us know how Open Access to this research benefits you.

This is a pre-publication author manuscript of the final, published article.

Terms of Use

This article is made available under the terms and conditions applicable towards Open Access

Policy Articles, as set forth in our Terms of Use.

\section{Citation/Publisher Attribution}

Ashley, C., Gillespie, E. A., \& Noble, S. M. (2015). The Effect of Loyalty Program Fees on Program Perceptions and Engagement. Journal of Business Research, 69(2), 964-973.

Available at: http://dx.doi.org/10.1016/j.jbusres.2015.09.001 


\section{THE EFFECT OF LOYALTY PROGRAM FEES ON PROGRAM PERCEPTIONS AND}

\section{ENGAGEMENT}

Christy Ashley, The University of Rhode Island

Erin A. Gillespie, Elon University

Stephanie M. Noble, The University of Tennessee

Forthcoming in Journal of Business Research

Ashley, C., et al., The effect of loyalty program fees on program perceptions and engagement, Journal of Business Research (2015), http://dx.doi.org/10.1016/j.jbusres.2015.09.001

Abstract

Retailers may introduce loyalty program enrollment fees for several reasons, including to offset the costs of the program. The principle of commitment-consistency and sunk cost effects suggest consumers who pay a fee have a higher value to the firm and exhibit behavioral loyalty, while the zero-price effect predicts the opposite. Three studies show: consumers who pay to participate in a loyalty program have more favorable attitudes, more positive evaluations of value for the money and benefits than non-paying members (Study 1); and altering the wording of denominations of accrual can affect willingness to join fee-based programs (Studies 2 and 3). The results suggest a boundary effect to the numerosity heuristic. Presenting reward credit accumulations in higher numbers may be advantageous when program fees are high, since it shifts the focus of processing from the fee to the rewards. However, standard units may be more favorable when program fees are low.

Keywords: loyalty programs, fee-based loyalty programs, denominations of accrual, numerosity, expectancy-value, loyalty program structure 


\section{The Effect of Loyalty Program Fees on Program Perceptions and Engagement}

\section{Introduction}

According to BusinessWeek, 90\% of Americans participate in at least one loyalty program (McKee, 2007) which offers benefits in exchange for repeat patronage to an organization (Rust, Zeithaml, \& Lemon, 2000). Consumer participation in loyalty programs also benefits firms, since a loyalty program can "accelerate the loyalty life cycle, encouraging a $1^{\text {st }}-$ or $2^{\text {nd }}$-year customer to behave like the company's most profitable $10^{\text {th }}$-year customer" (Yi \& Jeon, 2003, p. 230). Firms gain data that helps them customize offerings and optimize their strategies.

Firms are interested in maximizing the return associated with loyalty programs. In an effort to cover some program costs, some service providers have moved from free to fee-based loyalty programs (Gaffney, 2008). Examples include AMC Theatres Stubs Program, REI Membership, Ruth’s Chris FOS Diner Rewards, AirAsia BIG Loyalty Program, Amazon.com, and Barnes \& Noble.

The extant literature suggests fee-based loyalty programs may be evaluated differently from free programs. However, most of the existing research emphasizes free programs and post-enrollment outcomes, including store loyalty and program recommendations. Less is known about the evaluation of fee-based programs and the role of fee-based loyalty program media (like points, stamps, or visits) in the decision to initially join the loyalty program.

We contribute to our understanding of fee-based loyalty programs using three studies. First, we address conflicting predictions about whether consumers who pay fees have more favorable evaluations and self-reported purchase behaviors than consumers who join loyalty programs for free (Study 1).

Second, we investigate ways to increase the likelihood that consumers will enroll in a fee-based program (Study 2). Study 3 investigates the effect of the fee and media (how credits toward rewards are tracked) on engagement in fee-based loyalty programs in a controlled, experimental setting. 
The paper aims to answer the following research questions:

1) How do loyalty program fees change consumer perceptions?

2) How does the loyalty program structure interact with loyalty program fees to affect customer engagement?

Following the theoretical background, hypotheses are developed. Study 1 aims to demonstrate how consumers evaluate fee-based programs, but does not suggest how to increase enrollment in such programs. Therefore, we utilize the expectancy-value theory and previous work on reinforcers as a conceptual framework for Study 2 to show how retailers can change program structure to increase initial engagement in fee-based loyalty programs. Specifically, we look at how the wording of denominations of accrual can affect fee-based program enrollment intentions. A participant in a loyalty program accumulates denominations of accrual (e.g., stamps, points, dollars) to attain a reward. Study 2 varies what the customer accumulates versus the price of the fee-based program to understand how program structure can influence value judgments that affect intentions to engage in fee-based loyalty programs. Study 3 aims to replicate the results of Studies 1 and 2 in a different, controlled context. The results are followed by a general discussion, including limitations and directions for future research.

Thus, the manuscript contributes as it sheds light on how loyalty program structure affects enrollment decisions. It extends the literature on medium maximization, which suggests that consumers focus on maximizing points, but did not separate immediate purchase decisions (an enrollment fee) from future reward accumulation. Third, we identify the size of initiation fee as a moderator that affects the relationship between points and willingness to pay a loyalty program enrollment fee. The results suggest there may be a boundary condition to the use of the numerosity heuristic, and that consumers may prefer to see rewards tracked using simpler terms or the default unit ( 1 point $=1$ dollar spent $)$ when programs are less expensive or free to join. 


\section{Theoretical Background}

Expectancy-value theory provides a theoretical framework for understanding consumer decisions to join and engage in fee-based loyalty programs. Expectancy-value theory's basic tenet is that individuals engage in behaviors that they perceive to be most likely to yield valued rewards based on an analysis that benefits exceed costs (Smith \& Vogt, 1995; Wigfield \& Eccles, 2000). It suggests commitment-consistency and sunk cost effects can affect the way the consumer evaluates costs and benefits. The existing literature suggests that consumers prefer attitudes and behaviors that are consistent with past choices (Swann, Stein-Seroussi, \& Giesler, 1992; Cialdini, 2001). For example, consumers may use observations of their previous behaviors, like paying to enroll in a loyalty program, to make inferences about their attitudes toward the firm that offers the program (Bem, 1967).

Insert Figure 1 about here

Loyalty program structures vary dramatically and can affect consumers' purchase frequencies and volumes (see Bijmolt, Dorotic \& Verhoef, 2010). Previous research examines loyalty program tiers (e.g. Dréze \& Nunes, 2009), reward timing (e.g. Yi \& Jeon, 2003), reward type (e.g. Melancon, Noble, \& Noble, 2011), reward value (e.g. Kivetz, 2003), behavior before and after redemptions (e.g. Nunes and Drèze, 2011), and the redemption policy of rewards (e.g. Smith \& Sparks, 2009). Less is known about the structural component of a program fee.

Another structural component is the accumulation of credits toward the award, or the medium used to track purchase behavior (e.g. points, dollars, purchases, etc.). The medium used to track progress toward a reward does not have any value on its own, but can be traded for a desired outcome (Hsee, Yu, Zhang, \& Zhang, 2003). Consumers should focus their decisions on the relationship between effort and the end outcome, but sometimes they attempt to maximize the effort to medium return (medium maximization) (Hsee et al., 2003). The nominal medium presents an illusion of advantage, an 
illusion of certainty, or an illusion of linearity (Van Osselaer, Alba, \& Manchanda, 2004; Nunes \& Dreze, 2006).

The numerosity heuristic, where people focus on numbers rather than the units in which the quantity is represented, leads to errors in estimation that affect how we make progress toward goals and how we perceive things. People generally prefer larger numbers and larger numbers can affect consumer perceptions (e.g. Nejad \& Onay, 2014; Hsee et al., 2003; Bagchi \& Li, 2011). However, Lembregts and Pandelaere (2013) note that standard units can be easier to process than large numbers, so it is important to understand the role of media numerosity in decisions to engage in fee-based loyalty programs.

Behavioral learning theory, which suggests primary and secondary reinforcers direct decision making, is also relevant (Rothschild \& Gaidis, 1981). Primary reinforcers, such as a money, have intrinsic utility. Secondary reinforcers, such as tokens, coupons, and trading stamps earned with purchases, have no such utility and must be converted (Rothschild \& Gaidis, 1981). Studies 2 and 3 examine how the media used affect intentions to engage. We hypothesize how these theories affect feebased loyalty program evaluation.

\section{Hypotheses Development}

Anecdotal reports suggest that consumers who pay fees to participate in loyalty programs are high value customers (e.g. Tuttle, 2011). Considering expectancy-value theory and the principle of consistency with previous commitments, consumers who have made a greater commitment to a loyalty program should have more favorable attitudes toward a loyalty program. Therefore, consumers who invest an enrollment fee in a loyalty program are more likely to report favorable attitudes toward the program than consumers with a lower commitment who enrolled for free. Similarly, signaling theory suggests programs with higher fees signal higher quality or value (Zeithaml, 1988). Thus, fee 
investment should increase loyalty program usage. The sunk cost effect (Thaler, 1980) suggests a similar pattern: consumers who pay to enroll consider return on the past investment as a benefit, so they are loyal to maximize the benefits of the program. As a result, we anticipate that consumers who have invested a fee into a loyalty program will exhibit greater behavioral loyalty toward the program.

We expect the increased investment into the loyalty program to change the way fee-based consumers evaluate the benefits of membership and the overall value (gives vs. gets) associated with program membership. The increased investment should result in a more thorough analysis of whether the program is good or bad (Wigfield \& Eccles, 2000). Simonson, Carmon and O'Curry (1994) suggest that consumers may infer negative associations when prices are low or when products are free. Moreover, consumers are likely to evaluate the program benefits and the overall value in a way that is consistent with their commitment.

The zero-price effect predicts the opposite result. Past research on the zero-price effect suggests there is an affective benefit associated with a free program, while fees make membership less attainable and less desirable. Free pricing seems to increase consumers' evaluations of the benefits associated with the offering, which increases consumer demand for the offering beyond its actual benefits (Shampanier, Mazar \& Ariely, 2007). If the zero-price effect applies to the context of loyalty programs, free loyalty programs will result in more favorable attitudes relative to fee-based programs, resulting in increased behavioral loyalty, greater perceived benefits, and higher perceptions of value after enrollment. On the other hand, the influence of commitment-consistency and sunk cost effects suggest fees will result in favorable loyalty program evaluations.

To help resolve this conflict in the literature, we propose that consumers who pay a fee are likely to focus more on the program benefits and perceive a greater value associated with program 
membership. The norm is for programs to be free, so the zero-price effect is less likely to impact processing since it is in line with expectations.

More formally,

H1: Consumers who pay a fee for a loyalty program will

(1a) have more favorable attitudes toward the program

(1b) have higher behavioral loyalty toward the retailer

(1c) focus more on the benefits of being enrolled in the program and

(1d) perceive the program as a better value than consumers who enroll in the program for free.

Loyalty programs vary in terms of what accumulates (points, stamps, purchase occasions, etc.), or denominations of accrual. Previous research shows differences in the endowed progress effect between points and purchases (Nunes \& Dréze, 2006) and indicates consumers feel they are getting something for free in the redemption of points (Smith \& Sparks, 2009). However, it is not clear whether consumers' evaluations of loyalty programs differ based on what consumers accumulate when a program fee is present. According to expectancy-value theory, consumers will be drawn to programs where the benefits outweigh the costs, which include the fee.

One way to alter these value judgments is in the denominations of accrual. In a loyalty program context, the accumulation of points should lack utility because they are useless unless converted. The conversion might only need to be mental, but it is still likely to reduce the perceived value of what the consumer accumulates (Rothschild \& Gaidis, 1981), which could reduce program engagement. On the other hand, when consumers do not need to convert denominations of accrual into dollars, it should enhance the cost/benefit ratio and increase program engagement. It is not clear how increased membership fees or point accruals influence these relationships.

Van Osselaer, Alba, and Manchanda (2004) demonstrated that people do not always engage in rational conversion when faced with a point-based system. A more simplistic comparison (1 dollar for 1 point) accrual system allows the consumers to easily see how much money they need to spend before 
obtaining a reward, so it should not tax the consumer's mental processing and they would likely process it similarly to a primary reinforcer (i.e. money accrual). In this case, there would be heightened joining intentions, relative to more taxing conversions, because there are no delayed gratification feelings.

However, simplistic conversions might backfire on the retailer/service provider if the program is more costly because it allows the consumers to focus on the price of joining the program. As the price of the loyalty program increases, joining intentions are likely to go down for easy conversion programs. If the conversion of the accrual requires more work on the part of the customer (e.g., for every 1 dollar spent the consumer might get 100 points), more holistic processing during the value analysis should reduce consumers' focus on the cost of the program, which could increase joining intentions for feebased programs with higher fees. Programs with higher fees should signal higher quality or value to the consumer (Zeithaml, 1988). Thus, if a consumer is focusing on costs and benefits, the benefits are likely to be seen as more enticing in a more expensive program since these programs should be higher quality.

As such, we expect differences between more simplistic $(1$ dollar spent $=1$ dollar or 1 point accrued) and more taxing accrual systems ( 1 dollar spent $=100$ points accrued) for different levels of fee-based programs ( $\$ 5$ vs. $\$ 10)$. An accrual system that requires a larger conversion should lead to higher joining intentions in higher priced programs, whereas the opposite pattern should occur in more simplistic conversion system. More formally,

H2: There will be an interaction for type of denominations of accrual with the price of the program such that:

H2a-b: With more simplistic (a) dollar and (b) 1 point accrual programs, consumers' likelihood of joining will be higher when the price of joining is $\$ 5$ versus $\$ 10$.

H2c: With a more complex 100 point accrual program, consumers' likelihood of joining the program will be higher when the price of joining is $\$ 10$ versus $\$ 5$.

\section{Study One Method}


To test hypothesis 1 , we utilized an online survey method. We used a consumer panel that rewarded adult consumers with a cash payment in exchange for their participation in the study. We screened respondents based on their residence in the United States and their participation in the Amazon Prime loyalty program, which is the reward program context for Study 1. Amazon Prime is a fee based loyalty program that offers free or discounted shipping on selected items and special deals for members. The annual cost of the program ranged from $\$ 39-\$ 79$ and offered a free trial period of six months to a year. Thus, the Amazon Prime program provided an opportunity to compare consumers who were participating in the Amazon Prime program for free to consumers who were participating for a fee.

\subsection{Sample}

Study respondents were 310 adults from a national sample. The respondents were almost evenly split in terms of gender (51.1\% female, $49.9 \%$ male) and $80.7 \%$ were between the ages of 18 and 33 . Of the respondents, $40.6 \%$ participated in the Amazon Prime program for free and the remaining 59.4\% paid a membership fee. Among all respondents, $57.4 \%$ were in their first year as program members.

\subsection{Measures}

Table 1 contains the multi-item scales (7-point scales) used in this study and their properties. We created an index score for each multi-item scale by taking the average of the respective items for each. Insert Table 1 about here

In addition to the measures used to describe the sample, we used single items to capture: average spent in a given month (dependent variable); average spent in a single transaction (dependent variable); average number of transactions in a month (dependent variable); perceived monetary value of the program benefits in the previous month (dependent variable), and whether they would rejoin the program when their current membership expired. Respondents also answered open ended items that asked why they joined the program and how it changed their shopping behavior. 


\section{Study One Results}

\subsection{Hypotheses Tests}

Hypothesis 1a, which predicts consumers who pay a fee for a loyalty program will have more favorable attitudes toward the program, was supported $(\mathrm{F}(1,304)=4.92, \mathrm{p}<.05)$. Consumers who paid a fee had significantly more favorable attitudes toward the program $(M=6.18)$ than consumers who did not pay the fee $(M=5.97)$ (please see Table 2).

Hypothesis $1 \mathrm{~b}$, which predicts consumers who pay a fee will have greater behavioral loyalty toward the retailer, was also supported $(\mathrm{F}(1,304)=30.79, \mathrm{p}<.001)$. Consumers who paid a fee had significantly higher behavioral loyalty ratings $(M=5.87)$ than consumers who did not pay $(M=5.14)$. A comparison of self-reports of average monthly spending, individual transaction amounts, and number of transactions per month indicates that their individual transaction sizes did not differ significantly $(\mathrm{p}>$ .10), but they reported higher average spending in a month $(\mathrm{M}=\$ 78)$ than consumers who did not pay a fee $(\mathrm{M}=\$ 53)(\mathrm{F}(1,304)=10.18, \mathrm{p}=.002)$, which was likely driven by more frequent transactions from consumers who paid a fee $\left(\mathrm{M}_{\text {fee }}=2.75\right.$ transactions per month vs. $\left.\mathrm{M}_{\text {free }}=2.08\right)(\mathrm{F}(1,304)=6.89, \mathrm{p}<$ $.01)$.

Hypothesis 1c, which predicts consumers who pay a program fee will perceive the benefits associated the program to be greater than consumers who did not pay a fee, was supported $(\mathrm{F}(1,304)=$ 7.93, $\mathrm{p}<.01)$. Consumers who paid a fee were more focused on the benefits associated with the program $(M=5.93)$ than consumers who did not pay a fee $(M=5.67)$. Consumers who paid the fee also perceived greater monthly savings as a result of the program $(M=\$ 14)$ than consumers who did not pay a fee $(M=\$ 10)(F(1,304)=19.57, p<.001)$.

Finally, hypothesis $1 \mathrm{~d}$ predicts consumers who pay a program fee will perceive the program to be a better value than consumers who did not pay a program fee. The data supported hypothesis $1 \mathrm{~d}(\mathrm{~F}$ 
$(1,304)=31.59, \mathrm{p}<.001)$. Consumers who paid a fee evaluated the program at a better value $\left(\mathrm{M}_{\mathrm{fee}}=\right.$ 5.79 vs. $\mathrm{M}_{\text {free }}=5.12$ ).

\subsection{Post Hoc Analysis}

To further understand the relationship between attitudes toward the program, perceived benefits, perceived value, behavioral loyalty, and fee consideration (how much they currently paid to enroll in the program), we regressed the single-item dependent variable that asked how likely they were to rejoin the program when their current membership expired (either at the end of the free trial period or the end of their annual membership) on these variables. We retained age, children in the household and family income as covariates. We also included the length of their tenure in the program as a potential covariate. The results indicate that the independent variables and covariates explained $59.5 \%$ of the variance in intent to rejoin the program. Attitude toward the program $(t=2.71, \mathrm{p}<.01)$, behavioral loyalty $(\mathrm{t}=4.11$, $\mathrm{p}<.001)$, perceived value $(\mathrm{t}=6.65, \mathrm{p}<.001)$, current program cost $(\mathrm{t}=8.55, \mathrm{p}<.001)$, and years in the program $(\mathrm{t}=2.03, \mathrm{p}<.05)$ were significant predictors of future intent to join. The other variables, including the other covariates, were not significant ( $p s>.20)$.

Insert Table 2 about here

\section{Study One Discussion}

Study 1 suggests the fee-based program may correlate with greater revenue for the firm, both in terms of obtaining a fee from customers when they enroll in the program and in terms of increased revenue from behavioral loyalty and additional transactions. This gain depends on the loss of revenue from services offered for free (e.g. free shipping), does not consider the possibility that consumers who choose not to join may also reduce or eliminate patronage to the firm, and should be interpreted with the understanding that the higher transaction amounts were based on self-report data. That said, the results suggest increased behavioral loyalty and self-reported information about transactions are likely due to 
more favorable attitudes toward the program, its benefits, and the perceived value of participation. The results suggest the principle of commitment-consistency and sunk cost effect may be a more appropriate conceptual basis for understanding the effect of loyalty program fees after enrollment in a loyalty program than the zero-price effect.

Fee-based customers had greater differences in their perceptions of savings, behavioral loyalty, purchase behavior and, to a slightly lesser extent, program attitudes and perceived benefits. For the intent to rejoin post hoc analysis, consumers who have already paid report they are more likely to pay to rejoin again than consumers who are currently enrolled for free. Further, consumers who paid more reported higher intentions to rejoin the program than consumers who paid less.

The results do not capture the effect of awareness or perceptions around auto-enroll restrictions, wherein both fee- and free-based program consumers may need to opt out or rejoin automatically, but post hoc analysis indicates significant relationships between value, behavioral loyalty, attitude toward the program, and fee paid to intent to rejoin the program. The relationships between fee paid and intent to rejoin are stronger than relationships between attitudinal/perceptual variables and intent to rejoin. Even so, the analysis does not shed light on the underlying process. For example, do consumers consider the trade-off between program costs and benefits when they enroll in the program? And what affects the perceived costs and benefits associated with fee-based programs?

To build from the results and help marketers understand how they to gain more revenue from enrollments in fee-based loyalty programs, Study 2 increases our understanding of how program structure affects fee-based loyalty program enrollment decisions. Program structure elements, like denominations of accrual, are drivers of loyalty program effectiveness (McCall \& Voorhees, 2010).

\section{Study Two Methods}

\subsection{Subjects and Procedures}


Following a pretest, two hundred and eighteen students $(48 \%$ male; median age $=18-21)$ participated in exchange for course credit. We randomly assigned participants to one of six conditions composing a 3 (denomination of accrual: 1 dollar, 1 point, 100 points) x 2 (pricing of loyalty program: $\$ 5$ vs. $\$ 10$ ) between-subjects design. We asked participants to imagine that a local pizza restaurant (a relevant context) is offering a new loyalty program (Appendix A). After they read the scenario, they indicated their intentions to join the program on a 3-item scale, engaged in a thought listing procedure, and completed the remainder of the survey. Respondents were prompted to report both favorable thoughts and thoughts that were against joining.

\subsection{Measures}

The consumer's likelihood to join the program was the dependent variable, consisting of three items adapted from the scale used by Putrevu and Lord (1994). We assessed the agreement using a seven-point scale ( 1 = "strongly disagree"). The items included "I would enroll in the rewards program described in the scenario"; "The decision to join the reward program would be foolish" (reverse coded); and "Joining this reward program would be a good decision." Composite reliability for these three items was .95 and AVE $=.86$. Thus, we collapsed the items into a summated scale.

To determine whether the participants processed the message content pertaining to the points and dollars scenarios and the monetary cost to join the loyalty program, we asked them a few categorical questions. We deleted subjects failing to answer these questions correctly from analysis (seven respondents were deleted), leaving a final sample size of 211 subjects.

\section{Study Two Results}

\subsection{Experiment Results}

To examine hypothesis 2, we used univariate general linear model (GLM) with denomination of accrual (1 point, 100 points, 1 dollar), pricing of the program $(\$ 5, \$ 10)$ and their interaction as the 
independent variables and likelihood to join the program as the dependent variable. Since all our hypotheses included the directionality of the expected results, we used one-tailed tests in hypothesis testing. As expected, the results showed a significant interaction between the cost of program and denominations of accrual $[\mathrm{F}(2,199)=4.73, \mathrm{p}<.01]$ (please see Figure 2 for a graphical representation of the results).

\section{Insert Figure 2 about here}

To examine the specific pattern of results, we conducted planned comparisons. In the dollar accrual condition, the results showed a marginal decrease in joining intentions from the $\$ 5$ to $\$ 10$ condition $\left(\mathrm{M}_{\text {dollars }}=4.75\right.$ vs. $4.34, \mathrm{p}=.07$ respectively $)$ thus marginally supporting H2a. We found similar results for the 1 point condition. Joining intentions decreased from the $\$ 5$ to the $\$ 10$ fee condition $\left(\mathrm{M}_{1 \text { point }}=4.87\right.$ vs. $4.32, \mathrm{p}<.05$, respectively), supporting H2b. Finally, as expected, the results were opposite for the 100 points condition, where joining intentions increased as the cost of the program increased ( $\$ 5$ vs. $\$ 10 ; \mathrm{M}_{100 \text { points }}=4.36$ vs. $4.77, \mathrm{p}<.01$, respectively), supporting $\mathrm{H} 2 \mathrm{c}$.

Although not formally hypothesized, we expected that the participants would perceive the dollar and 1 point accrual condition similarly, which would obtain a similar pattern of results. As shown in Figure 2, there are no significant differences between dollar and 1 point accrual systems in the $\$ 5$ fee $\left(\mathrm{M}_{\text {dollars }}=4.75 ; \mathrm{M}_{1 \text { point }}=4.87, \mathrm{p}>.10\right)$ or the $\$ 10$ fee condition $\left(\mathrm{M}_{\text {dollars }}=4.34 ; \mathrm{M}_{1 \text { point }}=4.32, \mathrm{p}>.10\right)$, supporting our expectation.

Finally, we conducted post-hoc analyses to test whether the 100 point accrual condition significantly decreased joining intentions compared to the dollar and 1 point denominations of accrual in the $\$ 5$ condition, yet significantly improved consumers' joining intentions in the $\$ 10$ condition. These results show that the 100 point accrual program had the lowest joining intentions in the $\$ 5$ condition $\left(\mathrm{M}_{100 \text { points }}=4.36\right.$ vs. $\left.\mathrm{M}_{1 \text { point }}=4.87, \mathrm{p}<.01 ; \mathrm{M}_{\text {dollar }}=4.75, \mathrm{p}<.05\right)$, yet the highest joining intentions in 
the $\$ 10$ fee-based loyalty program $\left(\mathrm{M}_{100 \text { points }}=4.77\right.$ vs. $\mathrm{M}_{\text {dollars }}=4.34, \mathrm{p}<.05 ; \mathrm{M}_{1 \text { point }}=4.32, \mathrm{p}<.05$, respectively).

\section{Insert Table 3 about here}

\subsection{Thought Listing Results}

The thought listing results provide additional support for the hypothesized pattern of results. Two independent judges blind to the experimental conditions coded each respondent's thoughts as fee focused or cost/benefit focused to explore the mechanisms found in Study 1. An example of a feefocused thought is "The program seemed like a lot of money." An example of the cost/benefit theme is, "I had to assess if this was a good deal or not." There was extremely high agreement among the judges (reliability above .90), and disagreements were resolved through discussions.

An analysis of the thought listings revealed that respondents in the dollar and 1 point condition had similar patterns of thoughts as they evaluated whether to join the loyalty program (please see Table 4). The easier accrual programs seemed to lower joining intentions as the membership fee for the loyalty program increased. The larger membership fee increased respondents' thoughts about the membership fee ( $\$ 10$ vs. $\$ 5$ condition: dollar $-28 \%$ vs. $8 \% ; 1$ point $-20 \%$ vs. $9 \%$ ). However, this pattern did not emerge in the 100 point conditions. For the 100 point conditions, as the program becomes more expensive ( $\$ 5$ to $\$ 10)$, consumers thought more about the cost/benefit analysis ( $67 \%$ vs. $84 \%)$ and less about the membership fee (33\% vs. $16 \%)$.

\section{Insert Table 4 about here}

Taken together, the results suggest a simple conversion system (dollar and 1 point) allowed consumers to focus on other aspects of the program, such as the price of joining the program, but this backfired as the membership fee increased. When the denominations of accrual required more effort from the consumers (100 points), they placed more mental processing on cost/benefit assessments. The 
higher membership fee likely signals more benefits for the cost of the program, increasing joining intentions for these consumers over the other $\$ 10$ fee conditions.

\subsection{Summary}

These results show that there are differences in the likelihood that consumers will join fee-based loyalty programs based on the program fee and the wording of the denominations of accrual. In lower fee-based programs, framing accruement in dollars and simple point systems show the highest likelihood to join fee-based programs when the fee is nominal. In these programs, conversion is easiest and the attainment of a reward would seem easiest based on behavioral learning theory's primary vs. secondary rewards (Rothschild \& Gaidis, 1981). However, the likelihood that a consumer would join the program decreases as the price of the program increases. Consumers in these programs focus on the price of the program, presumably because the accrual conversion is quite easy, thus they can devote their attention to processing the cost of the program. When conversion of accrual becomes a little more taxing, consumers faced with more expensive membership fees for a loyalty program decrease their focus on the price of the program and increase a cost/benefit analysis, which results in more intentions to join the program when the program is more expensive than less expensive.

The results suggest consumers who pay a fee to participate in loyalty programs have more favorable attitudes toward the program, higher behavioral loyalty, focus more on the benefits associated with program enrollment, and perceive the program as a better value than consumers who enroll in a loyalty program for free. The results of study one were limited by the type of loyalty program, where the consumer may perceive membership as pre-payment for shipping. The Amazon.com brand name could also have influenced the results. Study 2 suggests that offering a higher level of points for each dollar spent can make consumers focus on the benefits associated with membership. However, it is limited because the reward offered was not in the same category as the product purchased. 
Therefore, Study 3 replicates the tests of hypotheses one and two using an experiment that is based on an actual fee-based loyalty program (at a retailer named REI) that provides credit toward free merchandise in exchange for participation. We test whether the results would be similar for an unknown brand and in a different category, and eliminate the potential for length of program participation to impact the results. We also wanted to test whether the type of reward offered might provide a boundary condition to the effects. If consumers were offered benefits that were in the same category (vs. the Amazon.com free shipping and streaming example), would paying a fee still result in positive program outcomes? A higher fee tests the boundary of the effect of denominations of accrual on joining a feebased program, and we controlled for involvement.

\section{Study Three Methods}

\subsection{Subjects and Procedures}

We used a consumer panel that rewarded adult consumers with a cash payment in exchange for their participation in the study. We screened respondents based on their residence in the United States, their participation in loyalty programs, in general, and asked for respondents who spend money on products for participation in outdoor activities like mountain biking, hiking, camping, and/or kayaking.

We used a $2 \times 2$ design that included scenarios that varied the fee (free, \$20) and the reward accrual (1 point for each $\$$ spent, 100 points for each dollar spent) with the same reward in all cases $(\$ 1$ toward a future purchase for each $\$ 10$ spent). The conditions were set to replicate the point vs. 100 points conditions in Study 2 with a different program type and higher fee. Please see Appendix B for descriptions of the loyalty program at an outdoor provision retailer.

We tested whether the fee had a main effect on attitudes toward the program, anticipated behavioral loyalty toward the retailer, the focus on the benefits associated with program enrollment, and perceptions of program value. We controlled for annual estimated expenditures in the outdoor provision 
category and involvement with the category as potential covariates. We also added a measure for the likelihood that they would rejoin the program for $\$ 20$ the following year, as well as an open-ended question to detect hypothesis guessing.

\subsection{Measures}

The measures mirror the items used in study 1 with slight changes in wording, with the addition of a category involvement scale $(\alpha=.81)$ and a single item to assess whether the respondent would pay $\$ 20$ to participate in the program described in the scenario.

\section{Insert Table 5 About Here}

We asked screening and filter question to see if respondents read the scenario and items carefully. We deleted subjects failing to answer these questions correctly from analysis (fifteen respondents were deleted), leaving a final sample size of 185 subjects.

\section{Study Three Results}

\subsection{Experiment Results}

To examine hypothesis 1, we used ANOVAs that included the full 2 (fee vs. free) x 2 (1 point vs. 100 points per dollar) model and included involvement, expenditures in the category, gender, age, and income as covariates for each of the following dependent variables: attitude toward the program, behavioral loyalty toward the firm, perceived value of the program, and perceived benefits associated with the program. All four overall models were significant (see Table 6). There were significant differences between the 1 point vs. 100 point manipulations, but the interactions between fees and denominations of accrual were not significant, so the main effects are reported. The results show support for hypotheses $1 \mathrm{a}, 1 \mathrm{c}$, and $1 \mathrm{~d}$, which suggest consumers who pay loyalty program fees have more favorable attitudes toward the program, its value, and the benefits associated with the program. Insert Table 6 About Here. 
To examine the effect of point accruals on joining intentions, we used a separate ANOVA with willingness to join the program for $\$ 20$ as the dependent variable. Since every respondent was posed the question about the program with the $\$ 20$ fee, we controlled for whether the respondent saw the program as free or fee-based in his/her scenario. Although the manipulation of the fee in the initial scenario was not significantly related to joining intentions, the manipulation of denominations of accrual was significant, such that respondents who accumulated 100 points per dollar spent had significantly higher joining intentions for the fee-based program.

\subsection{Summary}

The results provide support for the findings of the first two studies. The experiment tested hypotheses 1a-1d in a controlled setting and found similar results, with the exception of behavioral loyalty. The results also support the idea that consumers may be more willing to join a fee-based loyalty program with a higher fee when the points are accrued in higher numbers.

\section{General Discussion}

The purpose of this manuscript was to understand (1) whether consumers who paid loyalty program fees had more desirable attitudes and behaviors than consumers who enrolled for free and (2) how issues related to loyalty program structure (denominations of accrual) affect evaluations of feebased loyalty programs in an effort to answer the following questions:

How do loyalty program fees change consumer perceptions?

Study 1 found that desirable post-enrollment behaviors, including program utilization and program retention, were more likely to be driven by commitment-consistency and the sunk cost effect than the zero-cost effect. The results provided support for the idea that fee-based programs can help separate more desirable customers (either through screening or because paying a fee generates favorable behaviors). Study 1 is important because it compares self-reported purchase behavior, behavioral 
loyalty, and perceived value in a field setting. The greater average spending each month is likely to be of particular interest to managers.

While Study 1 suggests fee-based programs increase consumer revenue after enrollment (in addition to the revenue generated from the fee), it does not help managers understand how to get consumers to join these fee-based programs. Understanding how consumers evaluate fee-based program structures is critical for service providers because the evaluation may differentially affect cost/benefit assessments regarding the program, which ultimately influences joining intentions. Therefore, Studies 2 and 3 examine one type of program structure, denominations of accrual, to answer the second research question. Study 3 also suggests positive post-enrollment attitudes, perception of benefits and value in fee-based programs.

How does the loyalty program structure interact with loyalty program fees to affect customer engagement?

When membership fees are nominal (or free), dollar and 1 point accrual seem to be the best programs, as these programs lead to the highest joining intentions and keep the consumer focused on cost/benefit assessments of the program (rather than the price of the program). Simple accrual systems allow for easy conversions and should make the ultimate reward seem closer to obtaining and more attractive, enhancing the cost/benefit ratio (Rothschild \& Gaidis, 1981). The standard unit processing may be preferred (Lembregts \& Pandelaere, 2013). However, simple accrual systems seem to backfire when the cost of the loyalty program increases.

When the cost of the membership to the loyalty program increases, a more complex denominations of accrual system is likely to increase membership intentions. More complex systems tax consumers a bit more so they cannot easily determine the conversion of their accrual into rewards. This triggers a more holistic cost/benefit assessment of the program, which benefits programs with higher 
fees with higher intentions to sign up for the program. These results are consistent with signaling theory (Zeithaml, 1988). Thus, the benefits of these higher priced programs are likely to be seen as more enticing, so consumers focus on a cost vs. benefit analysis of the program. In general, the results show that joining intentions are highest when a focus is taken off the price of the program and instead placed on a cost/benefit analysis.

\subsection{Managerial Implications}

Our research suggests consumers who pay a fee to enroll in a loyalty program have more desirable perceptions of the program, and may have higher behavioral loyalty. Our research also suggests service managers should recognize the potential to use loyalty program structure to shift customer perceptions about the value of joining their loyalty programs. To summarize, service managers who wish to offer relatively low fee-based loyalty programs are likely to attract more members when they offer members the opportunity to accrue single dollars or points, while managers who wish to offer higher fee-based loyalty programs are more likely to attract members when they offer the accrual of multiple points per dollar spent.

Service providers offer loyalty programs with the goal of increasing loyalty and firm profitability. However, the customer needs to sign up for the loyalty program for the firm to have the information and offer the benefits that strengthen the exchange with customers. Our findings may be more important in the context of services where there is little differentiation (e.g. the credit card industry, see Wirtz, Mattila, \& Lwin, 2007). In these industries, the decision to join a loyalty program may have a greater impact on the customer's value to the firm by increasing perceptions of switching costs that increase behavioral loyalty. However, any firm that wants to increase membership in a program that utilizes a fee should examine its program structure.

\subsection{Theoretical Implications}


The results of the first study integrate signaling theory with expectancy-value theory's proposal that consumers are more likely to evaluate a program favorably if they feel motivated with the rewards relative to the costs (Cohen, Fishbein, \& Ahtola, 1972). The results suggest the fee may act as a cue of the program's value, which indicates a boundary to the benefits of a zero price effect.

These findings also extend the work on loyalty program structure (Nunes \& Dréze, 2006; Smith $\&$ Sparks, 2009), showing the denomination of accrual can differentially influence the likelihood that consumers will join fee-based loyalty programs. Decision makers tend to focus on nominal numbers and overlook their underlying values, resulting in a consumer preference for options that offer more "media" or points that are redeemable for something else (Hsee et al., 2013). Most of the research on medium maximization has studied how loyalty program points are presented affect consumer decision making related to the post-enrollment redemption of rewards (e.g. Kwong et al., 2011). In contrast, we extend the medium-maximization notion by proposing that the way the media (points, dollars, visits) are presented affect consumer willingness to join a fee-based program (incurring an immediate cost on the basis of the perceived attractiveness of future rewards). We show consumer preference for loyalty program options that offer a greater quantity of the medium in question interacts with program fees to affect loyalty program engagement. We find that standard units may improve program evaluations in standard (free) or lower cost loyalty program, perhaps due to improved processing fluency of programs that are a better value. This results suggests a boundary to numerosity effects in this context.

\subsection{Limitations and Directions for Future Research}

There are some limitations of this study worth noting. First, we used a survey in Study 1, so we show relationships and not causality. We asked for self-reported expenditures, not account histories. We used an experimental methodology to isolate the effects of loyalty program structure on joining intentions in Study 2. Past research has not established baseline results about the influence of program 
structure elements on intentions to join fee-based loyalty programs. Future research could look at other program structure elements (e.g. credits, timing, redemption, expiration, tiers, etc.) and test the program structure ideas in a more real-world setting.

Similarly, future research assessing the range and limits of the generalizability of this research is warranted with regard to the amount of the fee. There is likely a threshold where too high of a fee diminishes a cost/benefit assessment, whether the loyalty program is in multiple points, single points or dollars. The type of rewards given presents another limitation. Future research should examine program benefits that are more social in nature (convenience, status, VIP section, etc.) to determine if our effects hold.

Despite these limitations, this research effort is one of the first to address how loyalty program fees affect self-reported purchase behavior, loyalty and the way consumers process information about loyalty program structure as they decide whether or not to enroll. The results indicate that loyalty program fees change consumer expectations and behaviors in interesting ways. Customers who pay loyalty program fees may also have other characteristics that make them higher value to the firm, and the context consumers use to make decisions about joining a program depends on the program structure and cost. As such, this study offers several insights into the advantages of a fee-based loyalty program and how to design fee-based loyalty programs that could entice consumers to join. 


\section{References}

Ajzen, I., \& Fishbein, M. (1980). Attitudes and the attitude-behavior relation: Reasoned and automatic processes. European Review of Social Psychology, 11 (1), 1-33.

Bagchi, R., \& Li, X. (2011). Illusionary progress in loyalty programs: Magnitudes, reward distances, and step-size ambiguity. Journal of Consumer Research, 37 (5), 888-901.

Bem, D.J. (1967). Self-perception: An alternative interpretation of cognitive dissonance phenomena. Psychological Review, 74, 182-200.

Bijmolt, T.H.A., Dorotic, M., \& Verhoef, P.C. (2010). Loyalty programs: generalizations on their adoption, effectiveness and design. Foundations and Trends in Marketing, 5 (4), 197-258.

Cialdini, R.B. (2001). Influence: Science and practice. 4th edition. Needham Heights, MA: Allyn \& Bacon.

Cohen, J.B., Fishbein, M., \& Ahtola, O.T. (1972). The nature and uses of expectancy-value models in consumer attitude research. Journal of Marketing Research, 9 (4), 456-460.

Drèze, X., \& Nunes, J.C. (2009). Feeling superior: The impact of loyalty program structures on consumers' perceptions of status. Journal of Consumer Research, 35 (6), 890-905.

Gaffney, J. (2008). The myth of customer loyalty. 1to1 Magazine, August 5. Retrieved from http://www.loyaltylab.com/a/news/news_stories/08-0805/The_Myth_of_Customer_Loyalty.aspx?CntPageID=1.

Grewal, D., Monroe, K.B., \& Krishnan, R. (1998). The effects of price-comparison advertising on buyers' perceptions of acquisition value, transaction value and behavioral intentions. Journal of Marketing, 62 (2), 46-59.

Hsee, C., Yu, K., Zhang, J., \& Zhang, Y. (2003). Medium maximization. Journal of Consumer Research, 30 (1), 1-14. 
Hsee, C.K., Zhang, J., Cai, C.F., \& Zhang, S. (2013). Overearning. Psychological Science, 24 (6), $852-$ 859.

Kivetz, R. (2003). The effects of effort and intrinsic motivation on risky choice. Marketing Science, 22 (4), 477-502.

Kwong, J., Soman, D., \& Ho, C. (2011). The role of computational ease on the decision to spend loyalty program points. Journal of Consumer Psychology, 21 (2), 146-156.

Lembregts, C., \& Pandelaere, M. (2013). Are all units created equal? The effect of default units on product evaluations. Journal of Consumer Research, 39 (6), 1275-1289.

McCall, M., \& Voorhees, C. (2010). The drivers of loyalty program success: An organizing framework and research agenda. Cornell Hospitality Quarterly, 51 (1), 35-52.

McKee, S. (2007). The problem with loyalty programs. BusinessWeek, May 10. Retrieved from www.businessweek.com/print/smallbiz/content/may2007/sb20070510_406822.htm

Melancon, J.P., Noble, S.M., \& Noble, C.H. (2011). Managing rewards to enhance relational worth. Journal of the Academy of Marketing Science, 39 (3), 341-362.

Melnyk, V., \& Bijmolt, T. (2015). The effects of introducing and terminating loyalty programs, European Journal of Marketing, 49 (3/4), 398-419.

Nejad, M.R., \& Onay, S. (2014). Numerosity and cognitive complexity as moderators of the medium effect. Procedia Economics and Finance, 14, 445-453.

Nunes, J.C., \& Drèze, X. (2006). The endowed progress effect: How artificial advancement increases effort. Journal of Consumer Research, 32 (4), 504-512.

Nunes, J.C. \& Drèze, X. (2011). Recurring goals and learning: The impact of successful reward attainment on purchase behavior. Journal of Marketing Research, 48 (2), 268-281. 
Putrevu, S., \& Lord, K.R., (1994). Comparative and noncomparative advertising: Attitudinal effects under cognitive and affective involvement conditions. Journal of Advertising, 23 (2), 77-91.

Reynolds, K. E., \& Beatty, S.E., (1999). Customer benefits and company consequences of customersalesperson relationships in retailing. Journal of Retailing, 75 (1), 11-32.

Rothschild, M.L., \& Gaidis, W.C. (1981). Behavioral learning theory: Its relevance to marketing and promotions. Journal of Marketing, 45 (Spring), 70-78.

Rust, R.T., Zeithaml, V.A., \& Lemon, K.M. (2000). Driving customer equity: How customer lifetime value is reshaping corporate strategy. New York: The Free Press.

Shampanier, K., Mazar, N., \& Ariely, D. (2007). Zero as a special price: The true value of free products. Marketing Science, 26 (6), 742-757.

Simonson, I., Carmon, Z., \& O’Curry, S. (1994). Experimental evidence on the negative effect of product features and sales promotions on brand choice. Marketing Science, 13 (1), 23-40.

Smith, A., \& Sparks, L. (2009). It's nice to get a wee treat if you've had a bad week: Consumer motivations in retail loyalty scheme points redemption. Journal of Business Research, 62 (5), 542-547.

Smith, R.E., \& Vogt, C.A. (1995). The effects of integrating advertising and negative word-of-mouth communications on message processing and response. Journal of Consumer Psychology, 4 (2), 133-151.

Swann, W.B., Stein-Seroussi, A., \& Giesler, R.B. (1992). Why people self-verify. Journal of Personality and Social Psychology, 62 (3), 392.

Thaler, R. (1980). Toward a positive theory of consumer choice. Journal of Economic Behavior and Organization, 1 (1), 39-60. 
Tuttle, B. (2011). Amazon prime loses $\$ 11$ annually per member... and it's a huge success. Time, November 14. Retrieved from http://business.time.com/2011/11/14/amazon-prime-loses-11annually-per-member-and-its-a-huge-success/.

Van Osselaer, S.M.J., Alba, J.W., \& Manchanda, P. (2004). Irrelevant information and mediated intertemporal choice. Journal of Consumer Psychology, 14 (3), 257-270.

Wigfield, A., \& Eccles, J.S. (2000). Expectancy-value theory of achievement motivation. Contemporary Educational Psychology, 25, 68-81.

Wirtz, J., Mattila, A.S., \& Lwin, M.O. (2007). How effective are loyalty reward programs in driving share of wallet? Journal of Service Research, 9 (4), 327-334.

Yi, Y., \& Jeon, H. (2003). Effects of loyalty programs on value perception, program loyalty, and brand loyalty. Journal of the Academy of Marketing Science, 31 (3), 229-240.

Zeithaml, V.A. (1988). Consumer perceptions of price, quality, and value: A means-end model and synthesis of evidence. Journal of Marketing, 52 (July), 2-22. 
TABLE 1

Study 1 Scale Items and Metrics

\begin{tabular}{|c|c|c|c|c|c|}
\hline Items & Mean (std.) & Loading & $\begin{array}{l}\text { Cronbach's } \\
\text { alpha }\end{array}$ & AVE & $\begin{array}{l}\text { Composite } \\
\text { Reliability }\end{array}$ \\
\hline Attitude & & & .92 & .74 & .93 \\
\hline Att1: I think the program is a satisfactory program. & $6.00(.88)$ & .92 & & & \\
\hline Att2: I think the program has a lot of beneficial characteristics & $6.05(.93)$ & .90 & & & \\
\hline Att3: I have a favorable opinion of the program & $6.14(.85)$ & .92 & & & \\
\hline $\begin{array}{l}\text { Att4: The decision to join the program was foolish (reverse } \\
\text { coded) }\end{array}$ & $6.22(1.00)$ & .72 & & & \\
\hline Att5: Joining the program was a good decision & $6.06(0.89)$ & .82 & & & \\
\hline Behavioral Loyalty & & & .91 & .75 & .94 \\
\hline $\begin{array}{l}\text { Loy1: I am more likely to shop at Amazon.com because of the } \\
\text { benefits I get through the program }\end{array}$ & $5.98(1.11)$ & .88 & & & \\
\hline $\begin{array}{l}\text { Loy2: I am less likely to shop at other stores because I am } \\
\text { enrolled in this program }\end{array}$ & $5.43(1.39)$ & .83 & & & \\
\hline $\begin{array}{l}\text { Loy3: I shop at Amazon.com more frequently because I am } \\
\text { enrolled in this program }\end{array}$ & $5.72(1.27)$ & .94 & & & \\
\hline $\begin{array}{l}\text { Loy4: I am more likely to shop at Amazon.com in the future } \\
\text { because I am enrolled in this program }\end{array}$ & $5.83(1.13)$ & .84 & & & \\
\hline $\begin{array}{l}\text { Loy5: I go out of my way to buy things from Amazon.com } \\
\text { because I am enrolled in this program }\end{array}$ & $4.89(1.68)$ & .75 & & & \\
\hline Program Value & & & .72 & .65 & .85 \\
\hline Val1: This program is a good deal & $5.83(1.05)$ & .84 & & & \\
\hline Val2: The value of being a part of the program is clear to me & $5.90(1.06)$ & .85 & & & \\
\hline $\begin{array}{l}\text { Val3: The costs to join the program are greater than the benefits I } \\
\text { receive (reverse coded) }\end{array}$ & $4.81(1.78)$ & .71 & & & \\
\hline Program Benefits & & & .72 & .63 & .83 \\
\hline $\begin{array}{l}\text { Benefits 1: I focused on the benefits offered in this program when I } \\
\text { enrolled in the program }\end{array}$ & $5.85(.92)$ & .73 & & & \\
\hline $\begin{array}{l}\text { Benefits2: The benefits offered in the program were the most } \\
\text { important factor to me when formulating my opinion about the } \\
\text { program }\end{array}$ & $5.61(1.13)$ & .84 & & & \\
\hline $\begin{array}{l}\text { Benefits3: The benefits associated with this program are attractive } \\
\text { to me }\end{array}$ & $6.01(.81)$ & .81 & & & \\
\hline
\end{tabular}


TABLE 2

Summary of Results from Study 1

\begin{tabular}{|l|c|c|c|c|}
\hline Study 1 & \multicolumn{2}{|c|}{$\begin{array}{c}\text { Fee Mean vs. Free } \\
\text { Mean }\end{array}$} & $\begin{array}{c}\text { F- } \\
\text { value }\end{array}$ & p \\
\hline H1: Fee vs. Free & & & \\
\hline Hla: More favorable attitude towards program & 6.18 & 5.97 & 4.92 & $\mathrm{p}<.05$ \\
\hline H1b: Higher behavioral loyalty & 5.87 & 5.14 & 30.79 & $\mathrm{p}<.001$ \\
\hline H1c: Focus more on benefits & 5.93 & 5.67 & 7.93 & $\mathrm{p}<.01$ \\
\hline H1d: Perceive as better value & 5.79 & 5.12 & 31.59 & $\mathrm{p}<.001$ \\
\hline Post-hoc tests & & & $\mathbf{t}$ & $\mathbf{p}$ \\
\hline Favorable attitude $\rightarrow$ Re-join & & & 2.71 & $\mathrm{P}<.01$ \\
\hline Behavioral loyalty $\rightarrow$ Re-join & & & 4.11 & $\mathrm{p}<.001$ \\
\hline Perceived value $\rightarrow$ Re-join & & & 6.65 & $\mathrm{p}<.001$ \\
\hline Cost $\rightarrow$ Re-Join & & & 8.55 & $\mathrm{p}<.001$ \\
\hline Years $\rightarrow$ Re-Join & & & 2.03 & $\mathrm{p}<.05$ \\
\hline
\end{tabular}


TABLE 3

Summary of Results from Study 2

\begin{tabular}{|l|c|c|c|c|}
\hline Study 2 & \multicolumn{2}{|c|}{$\begin{array}{c}\mathbf{5 5} \text { Mean vs. \$10 } \\
\text { Mean }\end{array}$} & $\begin{array}{c}\text { F- } \\
\text { value }\end{array}$ & $\mathbf{p}$ \\
\hline H2: Type of denomination*Price $>$ Likelihood to join & & & 4.73 & $\mathrm{p}<.01$ \\
\hline & & & & $\mathbf{p}$ \\
\hline H2a: In 1 dollar: $\$ 5>\$ 10$ & 4.75 & 4.34 & & $\mathrm{p}=.07$ \\
\hline H2b: In 1 point: $\$ 5>\$ 10$ & 4.87 & 4.32 & & $\mathrm{p}<.05$ \\
\hline H2c: In 100 point: $\$ 5<\$ 10$ & 4.36 & 4.77 & & $\mathrm{p}<.01$ \\
\hline Post-hoc tests & $\mathbf{1}$ dollar & $\mathbf{1 p o i n t}$ & $\mathbf{1 0 0} \mathbf{p t s}$ & $\mathbf{p}$ \\
\hline \$5 condition & 4.75 & 4.87 & 4.36 & $\begin{array}{c}100: \$ 1 ; \mathrm{p}<.05 \\
100: 1 \mathrm{pt} ; \mathrm{p}<.01\end{array}$ \\
\hline \$10 condition & 4.34 & 4.32 & 4.77 & $\begin{array}{c}100: \$ 1 ; \mathrm{p}<.05 \\
100: 1 \mathrm{pt} ; \mathrm{p}<.05\end{array}$ \\
\hline
\end{tabular}


TABLE 4

Study 2: Thought Listing Results

\begin{tabular}{|l|c|c|}
\hline & Cost/Benefit Analysis & Focus on Membership Fee \\
\hline Condition: & $92 \%$ & $8 \%$ \\
\$10/dollars & $72 \%$ & $28 \%$ \\
\hline \$5/1 point & $91 \%$ & $9 \%$ \\
\$10/1 point & $80 \%$ & $20 \%$ \\
\hline \$5/100 points & $67 \%$ & $33 \%$ \\
$\$ 10 / 100$ points & $84 \%$ & $16 \%$ \\
\hline
\end{tabular}


TABLE 5

Study 3 Scale Items and Metrics

\begin{tabular}{|c|c|c|c|c|c|}
\hline Items & $\begin{array}{l}\text { Mean } \\
\text { (std.) }\end{array}$ & $\begin{array}{l}\text { Loadin } \\
\mathrm{g}\end{array}$ & $\begin{array}{l}\text { Cronbach' } \\
\text { s alpha }\end{array}$ & AVE & \begin{tabular}{|l|} 
Composite \\
Reliability \\
\end{tabular} \\
\hline Attitude & & & .95 & .76 & .97 \\
\hline Att1: I think the program is a satisfactory program. & $5.54(1.31)$ & .87 & & & \\
\hline $\begin{array}{l}\text { Att2: I think the program has a lot of beneficial } \\
\text { characteristics }\end{array}$ & $5.56(1.29)$ & .82 & & & \\
\hline Att3: I have a favorable opinion of the program & $5.64(1.34)$ & .91 & & & \\
\hline $\begin{array}{l}\text { Att4: The decision to join the program would be foolish } \\
\text { (reverse coded) }\end{array}$ & $5.76(1.44)$ & .75 & & & \\
\hline Att5: Joining the program would be a good decision & \begin{tabular}{|l|l|}
5.66 \\
$(1.32)$
\end{tabular} & .87 & & & \\
\hline Behavioral Loyalty & & & .89 & .75 & .90 \\
\hline $\begin{array}{l}\text { Loy1: I would be more likely to shop at this store because } \\
\text { of the benefits I get through the program }\end{array}$ & $5.52(1.36)$ & .87 & & & \\
\hline $\begin{array}{l}\text { Loy2: I would be less likely to shop at other stores because } \\
\text { I was enrolled in this program }\end{array}$ & $4.93(1.58)$ & .70 & & & \\
\hline $\begin{array}{l}\text { Loy3: I would shop at this store more frequently because I } \\
\text { was enrolled in this program }\end{array}$ & $\begin{array}{c}5.29 \\
(1.41)\end{array}$ & .92 & & & \\
\hline $\begin{array}{l}\text { Loy4: I would be more likely to shop at this store in the } \\
\text { future because I was enrolled in this program }\end{array}$ & $\begin{array}{l}5.46 \\
(1.30)\end{array}$ & .91 & & & \\
\hline $\begin{array}{l}\text { Loy5: I would go out of my way to buy things from this } \\
\text { store because I was enrolled in this program }\end{array}$ & $\begin{array}{l}4.83 \\
(1.59)\end{array}$ & .82 & & & \\
\hline Program Value & & & .77 & .67 & .84 \\
\hline Vall: This program is a good deal & $5.51(1.38)$ & .87 & & & \\
\hline $\begin{array}{l}\text { Val2: The value of being a part of the program is clear to } \\
\text { me }\end{array}$ & $5.87(1.22)$ & .87 & & & \\
\hline $\begin{array}{l}\text { Val3: The costs to join the program are greater than the } \\
\text { benefits I receive (reverse coded) }\end{array}$ & $4.99(1.97)$ & .75 & & & \\
\hline Program Benefits & & & .70 & .62 & .82 \\
\hline $\begin{array}{l}\text { Benefits 1: I focused on the benefits offered in this program } \\
\text { when I evaluated in the program }\end{array}$ & $5.92(1.15)$ & .87 & & & \\
\hline $\begin{array}{l}\text { Benefits2: The benefits offered in the program were the } \\
\text { most important factor to me when formulating my opinion } \\
\text { about the program }\end{array}$ & $5.54(1.29)$ & .78 & & & \\
\hline $\begin{array}{l}\text { Benefits3: The benefits associated with this program are } \\
\text { attractive to me }\end{array}$ & $5.57(1.35)$ & .73 & & & \\
\hline Likelihood to Join if program offered for \$20 & $4.07(1.89)$ & $\mathrm{n} / \mathrm{a}$ & $\mathrm{n} / \mathrm{a}$ & $\mathrm{n} / \mathrm{a}$ & $\mathrm{n} / \mathrm{a}$ \\
\hline Involvement & & & .81 & .69 & .89 \\
\hline $\begin{array}{l}\text { Involve1: I am highly involved in purchasing provisions } \\
\text { (supplies and apparel) for outdoor activities }\end{array}$ & $6.17(.86)$ & .83 & & & \\
\hline $\begin{array}{l}\text { Involve2: The purchase of provisions for outdoor activities } \\
\text { is not important to me (reverse coded) }\end{array}$ & $5.81(1.51)$ & .69 & & & \\
\hline $\begin{array}{l}\text { Involve3: I am passionate about purchasing provisions for } \\
\text { outdoor activities }\end{array}$ & $5.95(.94)$ & .91 & & & \\
\hline $\begin{array}{l}\text { Involve4: I enjoy purchasing provisions for outdoor } \\
\text { activities }\end{array}$ & $6.23(.79)$ & .87 & & & \\
\hline
\end{tabular}


TABLE 6

Summary of Results from Study 3

\begin{tabular}{|c|c|c|c|c|c|}
\hline \multirow{2}{*}{$\begin{array}{l}\text { Study } 3 \\
\text { H1: Fee vs. Free } \\
\end{array}$} & \multicolumn{3}{|c|}{ Free Means vs. Fee Means } & \multirow{2}{*}{$\begin{array}{c}\text { F- } \\
\text { value }\end{array}$} & \multirow[t]{2}{*}{$\mathbf{p}$} \\
\hline & Free & \multicolumn{2}{|c|}{ Fee } & & \\
\hline Hla: More favorable attitude towards program & 5.45 & \multicolumn{2}{|c|}{5.74} & 3.95 & $<.05$ \\
\hline & Free & \multirow{2}{*}{\multicolumn{2}{|c|}{ Fee }} & & \\
\hline H1b: Higher behavioral loyalty & 5.15 & & & .417 & $>.20$ \\
\hline & \multirow{2}{*}{$\frac{\text { Free }}{5.40}$} & \multicolumn{2}{|c|}{$\begin{array}{l}.20 \\
\text { Fee }\end{array}$} & & \\
\hline Hlc: Focus more on benefits & & \multicolumn{2}{|c|}{5.91} & 4.20 & $<.05$ \\
\hline & Free & \multicolumn{2}{|c|}{ Fee } & & \\
\hline H1d: Perceive as better value & 5.08 & \multicolumn{2}{|c|}{5.78} & 7.85 & $<.01$ \\
\hline \multirow[t]{2}{*}{$\begin{array}{l}\text { Comparison of joining intentions for fee-based } \\
\text { program }\end{array}$} & & \multicolumn{2}{|c|}{ Means } & & \\
\hline & & $\begin{array}{c}1 \\
\text { point }\end{array}$ & $\begin{array}{c}100 \\
\text { points }\end{array}$ & & \\
\hline Intentions to join the program described for $\$ 20$ & & 2.77 & 4.15 & 29.69 & $<.001$ \\
\hline
\end{tabular}




\section{FIGURE 1}

\section{Overview of Studies}

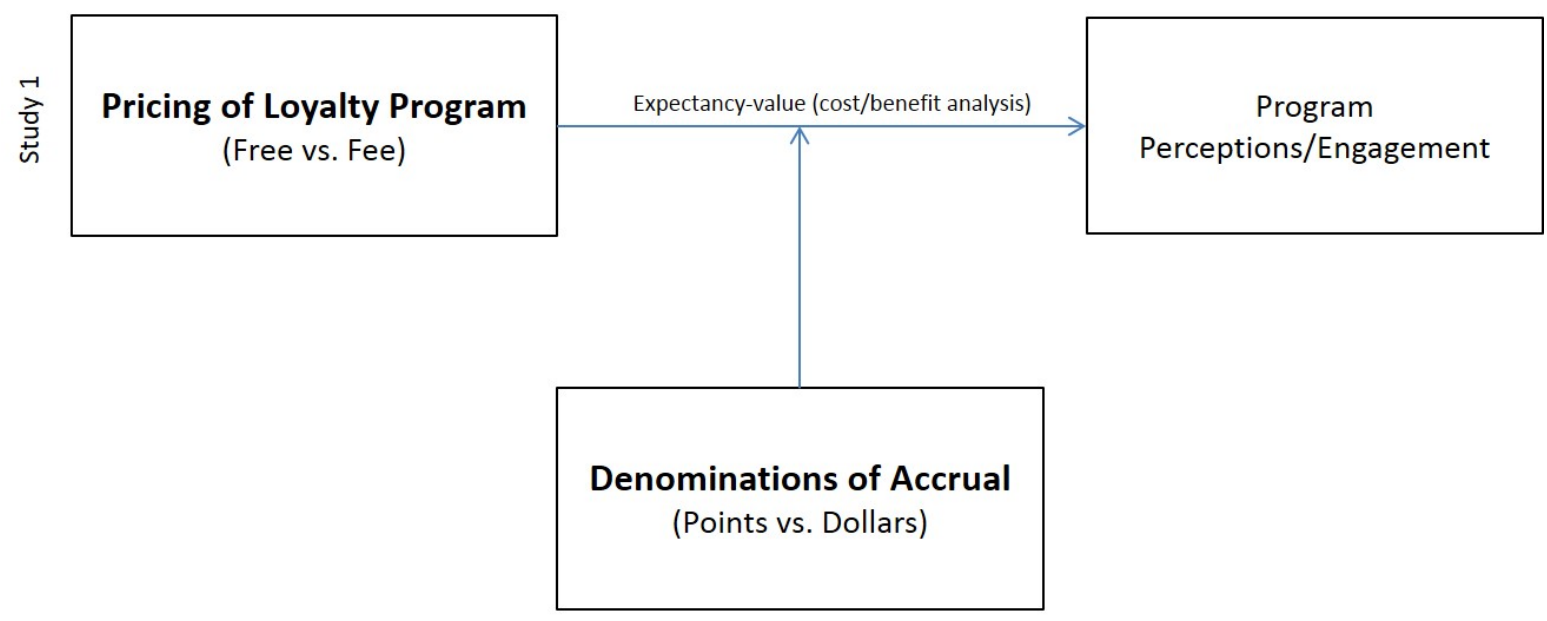

Studies $2 \& 3$ 
FIGURE 2

Study 2: Pricing of Program x Denominations of Accrual on Likelihood to Join (H2)

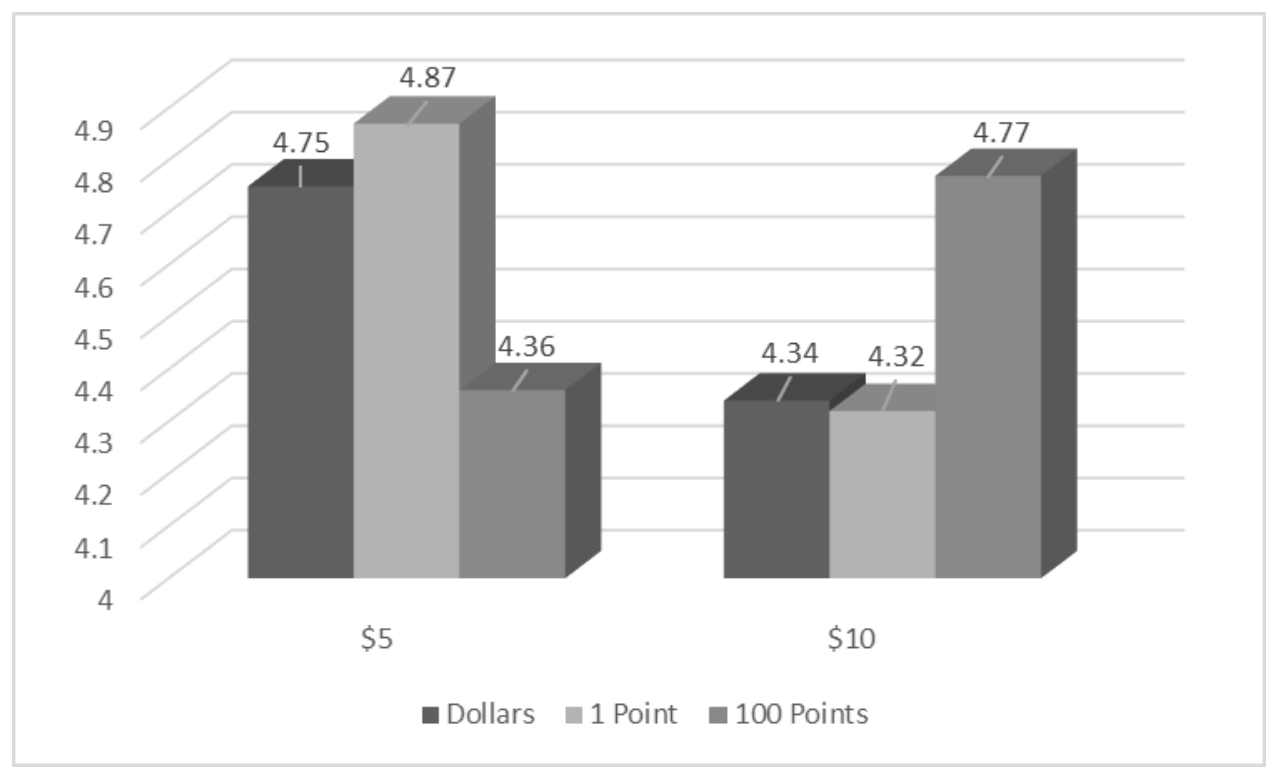




\section{APPENDIX A - SCENARIOS FOR STUDY 2}

\section{Dollar accrual condition:}

A pizza restaurant in town that delivers is offering a new reward program. To take advantage of this program, you will need to pay a $\$ 5$ membership fee to enroll.

After you enroll, the restaurant will keep track of the dollars you spend at the restaurant (not including the $\$ 5$ fee). You will earn $\$ 1$ toward the membership benefit for every $\$ 1$ you spend at the restaurant. You will receive 1 free movie ticket with a refreshment coupon to the movie theatre in town as your membership benefit when you accrue $\$ 50$ at the restaurant. There is no limit to the number of times you can receive the membership benefit in a given year.

Please advance to the next page and complete the questions in the survey.

\section{1 point accrual condition:}

A pizza restaurant in town that delivers is offering a new reward program. To take advantage of this program, you will need to pay a $\$ 5$ membership fee to enroll.

After you enroll, you will accrue 1 (one) point for every dollar you spend at the restaurant (not including the $\$ 5$ fee). You will receive 1 free movie ticket with a refreshment coupon to the movie theatre in town as your membership benefit when you accrue 50 points at the restaurant.

There is no limit to the number of times you can receive the membership benefit in a given year.

Please advance to the next page and complete the questions in the survey.

\section{0 point accrual condition:}

A pizza restaurant in town that delivers is offering a new reward program.

To take advantage of this program, you will need to pay a $\$ 5$ membership fee to enroll.

After you enroll, you will accrue 100 (one hundred) points for every dollar you spend at the restaurant (not including the $\$ 5$ fee).You will receive 1 free movie ticket with a refreshment coupon to the movie theatre in town as your membership benefit when you accrue 5,000 points at the restaurant. There is no limit to the number of times you can receive the membership benefit in a given year. Please advance to the next page and complete the questions in the survey.

*Note that only the $\$ 5$ conditions are shown for space purposes. For the $\$ 10$ condition, the "\$5 membership fee" was changed to "\$10 membership fee" and the "not including the $\$ 5$ fee" was changed to "not including the \$10 fee." 


\section{APPENDIX B: SCENARIOS FOR STUDY 3}

Imagine you are a customer of an outdoor provision provider, Store $\mathrm{X}$, that is local, convenient for you, and supplies the products you need for your outdoor activities (e.g. camping, hiking, hunting, rock climbing, kayaking, etc.).

Imagine you are currently a member of Store X's loyalty program, which cost you \$0 (\$20) to enroll. The program is designed so you earn 1 point (100 points) for every dollar you spend in the store. The store keeps track of your purchases.

Each time you collect 10 points (1,000 points), you earn $\$ 1$ in merchandise credit, which can be used on a future purchase at the store. The program also entitles members to special discounts on gear rentals and travel excursions. 